\title{
Observation of Classroom Performance Using Therapy Balls as a Substitute for Chairs in Elementary School Children
}

\author{
Molly E Burgoyne ${ }^{1}$, Caroline J Ketcham ${ }^{1}$, \\ ${ }^{1}$ Department of Exercise Science, Elon University, USA \\ Correspondence: Caroline J Ketcham, PhD 2525 Campus Box, Elon University, NC 27244, USA
}

Received: March 19, 2015 Accepted: April 17, $2015 \quad$ Online Published: April 30, 2015

doi:10.11114/jets.v3i4.730 URL: http://dx.doi.org/10.11114/jets.v3i4.730

\begin{abstract}
Many classrooms are beginning to substitute standard chairs with therapy balls, which help to improve students' focus and classroom performance, according to teacher and student reports. Researchers conducted an observational study in a classroom at a local elementary school that implemented therapy balls. For each hour-long observation, three independent researchers marked seated behaviors of students $(\mathrm{N}=19)$. The first observation was conducted when students were using standard chairs, and two more were conducted when students used therapy balls during classroom activities. Researchers observed the behaviors of students on the given seating device, including academic task (on/off task), effort level, attitude, interactions, seated behavior (bouncing/rocking/stationary/other), and intensity level of participation in classroom activities. Analysis of the collected data demonstrates that $50 \%$ of observations when students were seated on standard chairs indicated on task behavior, while $85 \%$ of observations when students were seated on therapy balls were recorded as on task behavior. In addition, movement while seated increased on the therapy balls $(35 \%$ of observations indicated stationary seated behavior) compared to the standard chairs ( $47 \%$ observations indicated stationary seated behavior). The increased rocking and bouncing seated behavior on the therapy balls suggests that the seating device helps to engage the vestibular system. In addition, stationary behavior on therapy balls was often classified as proprioceptive. The results from the observational study will allow researchers to further investigate whether or not engaging the vestibular system can help to improve performance on functional school skills.
\end{abstract}

Keywords: sensory integration, heightened sensory tools, vestibular, proprioception

\section{Introduction}

Effective sensory processing is vital to the learning process. The brain constantly receives sensory information from the environment; this sensory input is then processed by the brain to determine the appropriate response for a particular situation. Because the brain receives multiple sensory signals simultaneously, it must decide what sensory information is relevant to produce movement and disregard any extra sensory inputs. The brain then determines a plan and communicates with the appropriate muscles to produce an effective movement for the situation. In healthy individuals, this process of receiving sensory information, interpreting it, and producing an appropriate response occurs rapidly and constantly. However, for individuals who experience sensory processing differences, interpreting sensory information becomes difficult, causing challenges with the planning and production of appropriate responses for the environment.

Studies investigate different ways to improve daily living for individuals who experience sensory processing differences. In order to develop new technologies and treatment strategies for individuals with sensory processing differences, researchers must have an understanding of the three main sensory processing systems involved in daily functions. Visual input provides the brain with information about the surrounding environment, and the brain determines which visual information is important to consider in performing a task. In addition to visual input, the brain constantly receives proprioceptive input, which provides information about the relative position of neighboring parts of the body and the amount of effort and attention required for certain movements. As muscles in the body are activated, the brain receives information about the amount of force necessary to produce movement as well as the location of certain body segments in relation to others during movement. The brain also receives vestibular input, which provides information about the position of the head in space to help with balance and posture. Both vestibular and proprioceptive input are received in the brain and processed to produce precise, coordinated movements that meet environmental demands.

Recent studies determined that children with sensory-processing differences experience more difficulty with 
suppressing repeated or irrelevant sensory information than their typically developing peers (Pfieffer, Henry, Miller, \& Witherell, 2008). When individuals have difficulty processing sensory information within an environment, they may have trouble attending to relevant stimuli for adaptive behaviors such as learning (Lane, 2002). The prevalence of sensory processing disorders in children with various disabilities is reported to be as high as $40-88 \%$ (Ayres, 1989). In addition, among children without disabilities, the prevalence of sensory processing disorders ranges from 5 to $10 \%$ (Adrien et al, 1993; Dahlgren \& Gillberg, 1989; Kientz \&Dunn, 1997; Ornitz et al., 1997; Talay-Ongan \& Wood, 2000). For children in general, vestibular processing is in a developmental stage, so all children can have difficulty with sensory processing. This means that research on the role of heightened sensory input tools in classrooms has the potential to affect the learning environment of a large number of students, rather than strictly students with learning differences.

As more sensory information is received from the environment, more thought and attention is required for the brain to communicate with the rest of the body to produce an appropriate response. Some activities that provide increased proprioceptive and vestibular input have been identified as effective methods to improve sensory processing by increasing attention, and they are currently used in school-based settings. For example, many classrooms across the United States have begun to use therapy balls instead of chairs. Studies demonstrate that the use of therapy balls in classrooms is leading to increased focus and improved learning (Bagatell, Mirigliani, Patterson, Reyes, \& Test, 2010; Schilling and Schwartz, 2004; Schilling et al., 2003; Umeda \&Deitz, 2011). According to several studies, therapy balls appear to have a positive effect on in-seat behavior of students and create opportunities for effective instruction in the classroom (Bagattel et al., 2010; Schilling \& Schwartz, 2004; Schilling, Washington, Billingsley, \& Deitz,, 2003; Schaaf, Hunt, \& Benevides, 2012). Schilling and colleagues $(2003 ; 2004)$ have shown that teachers and students report a preference for therapy balls. Overall, research demonstrates that increasing sensory information received by the brain with therapy balls can help to improve the learning experience for students.

While studies that investigate the use of therapy balls in classrooms are limited, the existing literature on this topic suggests that therapy balls are valuable tools for the learning process. Studies demonstrate that after substituting therapy balls for standard chairs, there is general improvement in on-task behaviors (Capell, 2012; Haan, 2015). Results from these studies indicate that the use of therapy balls in a classroom setting is beneficial as long as students are given the choice of whether or not to use them and are trained to use them appropriately (Capell, 2012; Haan, 2015). Another study (Al-Eisa, Buragadda, \& Melam, 2013) investigated the effect of therapy ball seating on learning and sitting discomfort, and the authors concluded that sitting discomfort and performance of students improved while students were seated on therapy balls versus typical classroom chairs. A study using electroencephalography (EEG) demonstrated that therapy ball use helps to enhance attentional ability in students with ADHD (Wu et al., 2012). This study suggests that there is more to therapy ball seating than improving comfort and enhancing the learning atmosphere; there is a physiological mechanism at work that allows for improvements in attention and, in turn, performance on cognitive tasks. Current studies on therapy ball seating in classrooms support that many students feel more comfortable and focused while sitting on therapy balls than they do in standard chairs, leading to a more positive learning experience.

While research demonstrates that heightened sensory input is used in several classrooms to improve performance on cognitive tasks, the reason behind this tactic has not been examined. This study aims to understand the role of heightened sensory input in a classroom and to investigate why it is being used. The purpose of this study was to learn more about the physiological mechanisms that allow therapy balls to improve focus and performance in the classroom. Researchers predict that by introducing therapy balls into the classroom, students will be provided with more opportunities to engage their sensory systems; thus, they will also be able to demonstrate better focus during classroom activities.

\section{Method}

\subsection{Participants}

Nineteen students from a second grade classroom in North Carolina participated in this observational study. The teacher of this class received a grant to implement therapy balls into her classroom, so researchers were able to observe students with and without therapy balls. Students were observed during regular classroom activities. The protocol for this observational study was verified by the Elon University Institutional Review Board as exempt according to 45CFR46.101(b)(1): Educational Practices on 11/25/2013 and was approved by the teacher of the classroom and the principal of Hillsborough Elementary School.

\subsection{Observation One}

The first observation was conducted by three independent researchers with students on standard chairs. Each researcher marked the behavior of students over the course of one hour, which equated to a total of nine observations per student 
$(\mathrm{N}=19)$. Behaviors observed included academic task (on/off), effort level, attitude, interactions, intensity level of participation in classroom activities, and seated behavior (bouncing/rocking/stationary/other) (Table 1). For the purpose of developing an experiment, researchers were most interested in comparing the variables academic task and seated behavior with therapy balls in the classroom versus without therapy balls.

Table 1. Observed Behaviors for Observations 1 and 2

\begin{tabular}{|c|c|c|c|}
\hline & DEFINITION & & \\
\hline Academic & On task: & Off task: & \\
\hline Task: & $\begin{array}{l}\text { focused on the activity and } \\
\text { following classroom rules }\end{array}$ & $\begin{array}{l}\text { engaged in behaviors irrelevant } \\
\text { to the academic task }\end{array}$ & \\
\hline Effort Level: & $\begin{array}{l}\text { Effort: } \\
\text { student was active and willing } \\
\text { to participate, perhaps raising } \\
\text { his/her hand to answer questions }\end{array}$ & $\begin{array}{l}\text { Neutral: } \\
\text { student put minimum } \\
\text { effort into class activities }\end{array}$ & $\begin{array}{l}\text { Passive: } \\
\text { students who were unwilling to } \\
\text { do what was asked of them }\end{array}$ \\
\hline Attitude: & $\begin{array}{l}\text { Positive affect: } \\
\text { student appeared interested and } \\
\text { motivated in the assigned activity } \\
\text { and was enjoying the experience }\end{array}$ & $\begin{array}{l}\text { Neutral affect: } \\
\text { student did not express any feelings }\end{array}$ & $\begin{array}{l}\text { Negative affect: } \\
\text { student who looked bored, } \\
\text { unhappy, disinterested, or angry }\end{array}$ \\
\hline Interactions: & With teacher & With peers & None \\
\hline $\begin{array}{l}\text { Seated } \\
\text { Behavior: }\end{array}$ & $\begin{array}{l}\text { Rocking: } \\
\text { student moved back and forth or } \\
\text { side to side while sitting }\end{array}$ & $\begin{array}{ll}\text { Bouncing: } & \text { Stationary: } \\
\text { student was } & \text { student was sitting still } \\
\text { moving up } & \text { with both feet on the } \\
\text { and down floor } \\
\text { while seated }\end{array}$ & $\begin{array}{l}\text { Other: } \\
\text { behavior doesn't match a } \\
\text { category, but researcher describes } \\
\text { movement in notes }\end{array}$ \\
\hline Intensity: & $\begin{array}{l}\text { High: } \\
\text { student demonstrated high } \\
\text { energy, strength, and } \\
\text { concentration while participating } \\
\text { in classroom activities }\end{array}$ & $\begin{array}{l}\text { Moderate: } \\
\text { student demonstrated average energy, } \\
\text { strength, and concentration while } \\
\text { participating in classroom activities }\end{array}$ & $\begin{array}{l}\text { Low: } \\
\text { student demonstrated low energy, } \\
\text { strength, and concentration while } \\
\text { participating in classroom } \\
\text { activities }\end{array}$ \\
\hline
\end{tabular}

\subsection{Observation Two}

The second observation was conducted after the teacher of the classroom received a grant to buy her students therapy balls for seating. Students were observed performing classroom activities on therapy balls, and observations were recorded using the same variables for data collection as the first observation. Following the second observation, researchers determined that the most useful behavior categories to observe were academic task and seated behavior, so they developed modified data collection variables for the third observation to target these behaviors.

\subsection{Observation Three}

For the third observation, students were observed on therapy balls again with slightly modified variables. Researchers focused predominantly on the seated behaviors of students (Table 2).

Table 2. Observed Behaviors for Observation 3.

\begin{tabular}{|c|c|c|c|c|}
\hline VARIABLE & \multicolumn{4}{|c|}{ DEFINITION } \\
\hline Academic & \multirow{2}{*}{\multicolumn{4}{|c|}{$\begin{array}{l}\text { On task: } \\
\text { focused on the activity and following classroom } \\
\text { rules }\end{array}$}} \\
\hline Task: & & & & \\
\hline Interactions: & With peers & \\
\hline Seated & Rocking: & \multicolumn{3}{|l|}{ Bouncing: } \\
\hline Behavior: & $\begin{array}{l}\text { student moved back and forth or } \\
\text { side to side while sitting }\end{array}$ & $\begin{array}{l}\text { student was moving up and } \\
\text { down while seated }\end{array}$ & $\begin{array}{l}\text { student was } \\
\text { sitting still with } \\
\text { both feet on the } \\
\text { floor }\end{array}$ & $\begin{array}{l}\text { behavior doesn't match } \\
\text { a category, but } \\
\text { researcher describes } \\
\text { movement in notes }\end{array}$ \\
\hline Seated & W-sit: & Leaning: & Kneeling: & Shaking: \\
\hline Movement: & $\begin{array}{l}\text { student whose knees are rotated } \\
\text { inward and feet are placed } \\
\text { behind the ball, toes facing out, } \\
\text { so that the entire leg is in } \\
\text { contact with the ball }\end{array}$ & $\begin{array}{l}\text { student was supported by a desk, } \\
\text { the wall behind them, or another } \\
\text { classroom object, so that some } \\
\text { part of their body was resting on } \\
\text { a surface }\end{array}$ & $\begin{array}{l}\text { student was } \\
\text { kneeling on the } \\
\text { ball }\end{array}$ & $\begin{array}{l}\text { while sitting, the } \\
\text { student was moving } \\
\text { one or more limbs back } \\
\text { and forth or up and } \\
\text { down }\end{array}$ \\
\hline
\end{tabular}




\section{Results}

\subsection{Observation One}

Data from the first observation indicated that $47.17 \%$ of behavior on chairs was classified as stationary, $49.06 \%$ was "other", $1.29 \%$ was rocking, and 1.89\% was rocking (Figure 1). The behavior categorized as "other" was described by researchers as kneeling, leaning on the desk, or tapping feet.

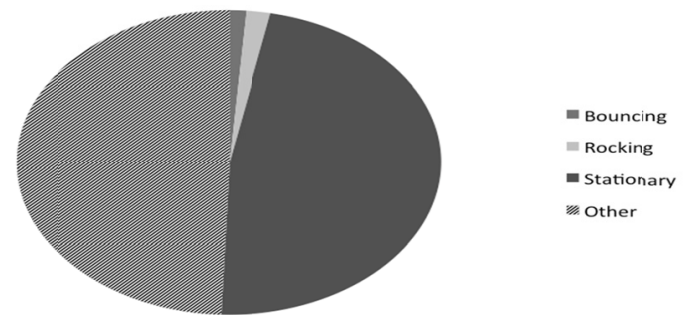

Figure 1. Seated Behavior without Therapy Balls 3.2 Observation Two

The second observation, conducted while students were sitting on therapy balls, indicated that $34.19 \%$ of behavior was stationary, $10.32 \%$ was bouncing, $13.55 \%$ was rocking, and $40 \%$ was classified as "other" (Figure 2). These results demonstrate that therapy balls provide more opportunities for students to perform rocking and bouncing behavior that standard chairs. During this observation, researchers noted that behaviors described as "other" could be described as kneeling, leaning, W sit, walking, and standing.

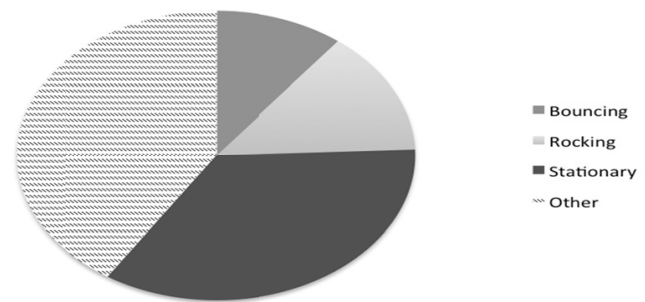

Figure 2. Seated Behavior with Therapy Balls

As Figure 3 indicates, $40 \%$ of "other" behavior was kneeling, $12.22 \%$ was $\mathrm{W}$ sit, $34.44 \%$ was leaning, $2.22 \%$ was walking, $4.44 \%$ was standing, and $6.67 \%$ was shaking limbs.

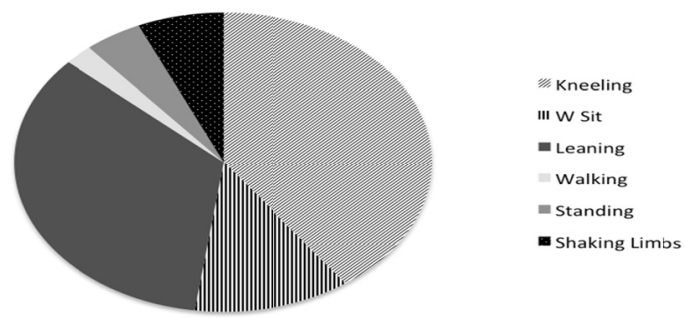

Figure 3. Types of "Other" Behavior Described with Therapy Balls

When results from the first and second observations were compared, it was found that therapy ball seating was correlated with increased on task behavior. Without therapy balls in the classroom, $50.31 \%$ of behavior observed was on task and $49.69 \%$ of behavior was classified as off task. On the other hand, when therapy balls were introduced to the classroom, $85.16 \%$ of behavior observed was classified as on task and $14.84 \%$ was off task.

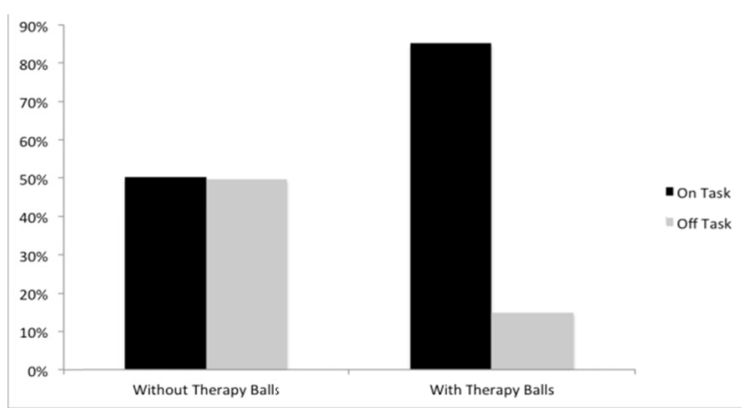

Figure 4. Comparison of Attention to Academic Task in a Classroom with and without Therapy Balls 


\subsection{Observation Three}

During the third observation, researchers focused on fewer variables, examining behavior on the therapy balls more closely. While the use of therapy balls clearly provided more opportunity for bouncing $(10.36 \%)$ and rocking behaviors $(23.83 \%), 64.77 \%$ of the behavior on the therapy balls was classified as stationary (Figure 5).

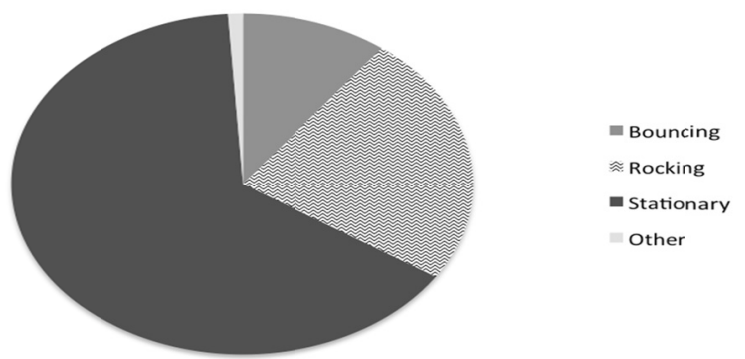

Figure 5. Behavior on Therapy Balls

Upon further examination, it was evident that stationary behavior could involve a variety of positions on the ball, including $\mathrm{W}$ sit, leaning, kneeling, and shaking. Kneeling and leaning were the two most commonly observed positions during the third observation, with $33.59 \%$ of behavior classified as kneeling and $45.04 \%$ as leaning. $12.98 \%$ of behavior observed was categorized as $\mathrm{W}$ sit and $8.4 \%$ of behavior involved shaking of the limbs (Figure 6).

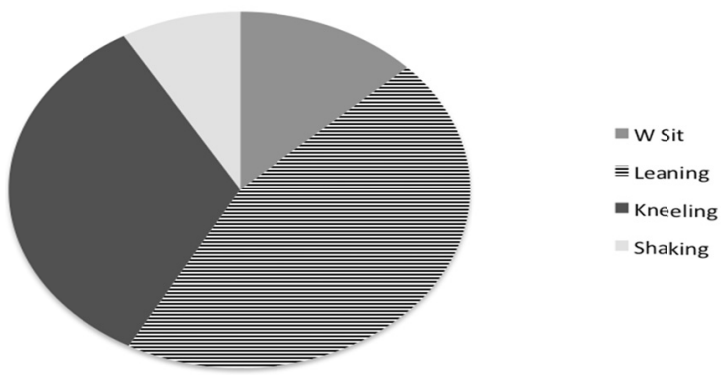

Figure 6. Position on Therapy Balls

The third observation demonstrated a similar trend to the earlier observations, which indicated that when students use therapy balls, they are more likely to be observed on task. $84.9 \%$ of behavior observed was classified as on task, while $15.1 \%$ of behavior was off task (Figure 7). As the third observation was conducted several months after the therapy balls were introduced to the classroom, it was noteworthy that students adapted to the new classroom environment. While early observations demonstrated that students performed vigorous movements on the ball, during the third observation, researchers noted that movements were much more subtle and controlled. It appeared that over time, students recognized the type of behavior that allowed them to perform at their best and were able to modify their movement on the balls to meet these needs.

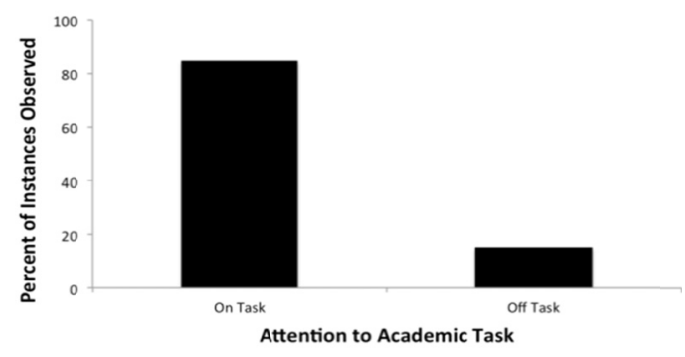

Figure 7. Observations of Students on Therapy Balls during Academic Task

\section{Discussion}

The data from this study provided researchers with information about the types of behaviors that students display on standard chairs versus therapy balls as well as the effect that therapy balls have on academic task. Results demonstrated that on task behavior increased significantly with the use of therapy balls. This is consistent with other studies investigating the use of therapy balls in classroom settings.

Studies indicate that there is a growing trend toward the use of therapy balls in classrooms to improve learning for students (AP, 2013; Bagatelli et al., 2010; Schilling \& Schwartz, 2004). A study investigating the efficacy of sensory integration therapy on children with autism found that the use of heightened sensory tools improved sensory integration 
as well as participation in home, school, and family activities (Schaaf, Hunt, \& Benevides, 2012). Studies examining the use of therapy balls in the classroom support that therapy ball seating may facilitate engagement and in-seat behavior to create opportunities for effective instruction (Schilling \& Schwartz, 2004; Schilling et al., 2003). This study also demonstrated that the use of therapy balls resulted in increased on task behavior, which has the potential to improve classroom performance and facilitate learning.

Research demonstrates that therapy balls have a positive effect on in-seat behavior for children who have vestibular or proprioceptive-seeking needs (Bagatelli et al., 2010). Results of this observational study support that therapy balls were most frequently used by students in a manner that provided extra proprioceptive and vestibular information. The increased rocking and bouncing behavior on the therapy balls compared to stationary chairs suggests that the therapy balls can be used to engage the vestibular system, which provides the brain with information about the position of the head in space to help with balance. The large number of observations that indicated kneeling, leaning, and W sit while seated on the therapy ball demonstrate that the therapy balls can also be used to provide increased proprioceptive input, which the body uses to understand the position of the limbs in space as well as the velocity and force with which the limbs move. Together, proprioceptive and vestibular inputs are used by the central nervous system to make adjustments in the muscles and joints that help to achieve coordinated movement and balance. Researchers hypothesize that by bombarding the vestibular and proprioceptive systems with increased input, sensory processing can be improved to help students achieve an appropriate response to classroom demands by focusing on relevant stimuli. When the sensory system has an overload of information, it is better able to select relevant input out of the extraneous information in order to produce appropriate responses to a given situation. This hypothesis should be investigated further in an experimental study to test the effect of proprioceptive and vestibular input on functional school tasks.

The application of heightened sensory tools in school settings is appropriate because education and academic success are highly valued in American society, and heightened sensory tools can help to improve learning for a wide range of students. 2.4 million students are diagnosed with learning disabilities in the United States, and 5-10\% of students without disabilities have some type of sensory processing disorder (AP, 2013). These statistics suggest that there is a large population of students that are in need of strategies to improve their learning experiences and support their differences. Unfortunately, classroom environments, especially in classrooms not specifically designated as "special needs classes", do not always address the needs of students with learning differences (AP, 2013). Incorporating therapy balls into the classroom environment is a simple strategy that can have a large impact on the learning experience of students.

Observations of students using therapy balls versus standard chairs indicate that therapy balls create more opportunities for sensory stimulation that ultimately result in higher frequencies of observed on task behavior. Thus, more research is necessary to investigate what type of sensory behaviors are most effective and through which physiological processes they work to improve focus and performance in the classroom. This observational study takes the first step in determining how and why heightened sensory tools are effective in improving the learning experience of students.

\section{Acknowledgements}

This study was conducted through the support of the Lumen Prize scholarship at Elon University. Special thanks to Kathleen Hupfeld and Julia Basiliere for their assistance in observations.

\section{References}

Adrien, J. L., Lenoir, P., Martineau, J., Perrot, A., Hameury, L., \& Larmande, C. (1993). Blind ratings of early symptoms of autism based upon family home movies. Journal of the American Academy of Child and Adolescent Psychiatry, 32(3), 617-626. http://link.springer.com/article/10.1007/s10803-007-0444-7

Al-Eisa, E., Buragadda, S., \& Melam, G. R. (2013). Effect of therapy ball seating on learning and sitting discomforts among Saudi female students. BioMed Research International. http://www.hindawi.com/journals/bmri/2013/153165/

A. P. The Associated Press. (2013, February 20). Yoga balls replacing desk chairs in some classrooms. New Jersey News. http://www.nj.com/news/index.ssf/2013/02/some_students_sitting_on_yoga.html

Bagatelli, N., Mirigliani, G., Patterson, C., Reyes, Y., \& Test, L. (2010). Effectiveness of therapy ball chairs on classroom participation in children with autism spectrum disorders. American Journal of Occupational Therapy, 64(6), 895-903. http://dx.doi.org/10.5014/ajot.2010.09149

Capell, B. (2012). Seating and time on task. Unpublished manuscript, Northwest Missouri State University, Maryville, MO. http://www.nwmissouri.edu/library/ResearchPapers/2012/Capell,\%20Brea.pdf

Dahlgren, S. O., \& Gillberg, C. (1989). Symptoms in the first two years of life: A preliminary population study of 
infantile autism. European Archives of Psychiatry and Neurological Science, 238(3), 169-174. http://dx.doi.org/10.1007/BF00451006

Haan, M. (2015, April). Stability balls and handwriting proficiency in a kindergarten classroom. Unpublished manuscript, Dordt College, Sioux Center, http://digitalcollections.dordt.edu/cgi/viewcontent.cgi?article=1085\&context=med_theses

Kientz, M. A., \& Dunn, W. (1997). A comparison of the performance of children with and without autism on the

Ornitz, E. M., Guthrie, D., \& Farley, A. H. (1977). The early development of autistic children. Journal of Autism and Childhood Schizophrenia, 7(3), 207-229. http://dx.doi.org/10.1007/BF01538999

Schaaf, R. C., Hunt, J., \& Benevides, T. (2012). Occupational therapy using sensory integration to improve participation of a child with autism: A case report. The American Journal of Occupational Therapy, 66(5), 547-555. http://dx.doi.org/10.5014/ajot.2012.004473

Schilling, D. L., \& Schwartz, I. S. (2004). Alternative seating for young children with autism spectrum disorder: Effects on classroom behavior. Journal of Autism and Developmental Disorders, 34(4), 423-432. http://dx.doi.org/10.1023/B:JADD.0000037418.48587.f4

Schilling, D. L., Washington, K., Billingsley, F. F., \& Deitz, J. (2003). Classroom seating for children with attention deficit hyperactivity disorder: Therapy balls versus chairs. American Journal of Occupational Therapy, 57(5), 534-541. http://dx.doi.org/10.5014/ajot.57.5.534

Sensory integration therapies for children with developmental and behavioral disorders. (2015, April). American Academy of Pediatrics.

http://pediatrics.aappublications.org/content/early/2012/05/23/peds.2012-0876.full.pdf + html

Sensory profile. American Journal of Occupational Therapy, 51, 530-537. http://dx.doi.org/10.5014/ajot.51.7.530

Talay, O. A., \& Wood, K. (2000). Unusual sensory sensitivities in autism: A possible crossroads. International Journal of Disability, Development and Education, 47(2), 201-212. http://dx.doi.org/10.1080/713671112

Wu, W., Wang, C., Chen, C., Lai, C., Yang, P., \& Guo, L. (2012). Influence of Therapy Ball Seats on Attentional Ability in Children with Attention Deficit/ Hyperactivity Disorder. Journal of Physical Therapy, 24(11). https://www.jstage.jst.go.jp/article/jpts/24/11/24_1177/_pdf

\section{$(\mathrm{cc}) \mathrm{EY}$}

This work is licensed under a Creative Commons Attribution 3.0 License. 